\title{
BMJ Open Urban green spaces and cancer: a protocol for a scoping review
}

\author{
Marion Porcherie, ${ }^{1,2}$ Mathilde Lejeune, ${ }^{1}$ Marion Gaudel, ${ }^{1}$ Jeanine Pommier, ${ }^{2}$ \\ Emmanuelle Faure, ${ }^{3}$ Zoé Heritage, ${ }^{4}$ Stéphane Rican, ${ }^{3}$ Jean Simos, ${ }^{5}$ \\ Nicola Luca Cantoreggi, ${ }^{5}$ Anne Roué Le Gall, ${ }^{1,2}$ Linda Cambon, ${ }^{1,2}$ \\ Jean-Philippe Regnaux ${ }^{1,6}$
}

To cite: Porcherie M, Lejeune M Gaudel M, et al. Urban green spaces and cancer: a protocol for a scoping review. BMJ Open 2018;8:e018851. doi:10.1136/ bmjopen-2017-018851

- Prepublication history and additional material for this paper are available online. To view these files, please visit the journal online (http://dx.doi. org/10.1136/bmjopen-2017018851).

Received 25 July 2017 Revised 31 0ctober 2017 Accepted 7 December 2017

Check for updates

${ }^{1}$ Department of Social Sciences and Health, School of Public Health, EHESP, Rennes, France ${ }^{2}$ ARENES (UMR/CNRS 6051), Université Rennes 1 Institut d'Etudes Politiques, Rennes, France

${ }^{3}$ LADYSS, Université Paris Nanterre, Nanterre, France ${ }^{4}$ French Healthy City Network, WHO, Rennes, France

${ }^{5}$ Institute of Global Health, University of Geneva, Genève, Switzerland

${ }^{6}$ CRESS U1153, METHODS team, Université Paris Descartes, Paris, France

Correspondence to Ms. Marion Porcherie; marion.porcherie@ehesp.fr, marionporcherie@hotmail.com

\section{ABSTRACT}

Introduction Green space in the built environment is an important topic on the health agenda today. Studies have shown that access to green spaces is associated with better mental and physical health, yet green spaces can also be detrimental to health if they are not managed appropriately. Despite the increasing interest in urban green spaces, little research has so far been conducted into the links between green spaces and cancer.

Objective The purpose of this scoping review is therefore to map the literature available on the types of relationship between urban green spaces and cancer.

Method and analysis We followed the Preferred Reporting Items for Systematic Review and Meta-Analysis Protocols 2015 guideline to report the protocol. To conduct this scoping review, we will use a structured search strategy based on controlled vocabulary and relevant key terms related to green space, urban space and cancer. We will search MEDLINE (PubMed), GreenFILE (EBSCOhost), Cumulative Index to Nursing and Allied Health Literature (EBSCOhost) and ScienceDirect as electronic database as well as hand-search publications for grey literature. This review will therefore provide evidence on this current topic, one which could have practical implications for policy-makers involved in choices which are more conducive to healthy living.

Ethics and dissemination No primary data will be collected since all data that will be presented in this review are based on published articles and publicly available documents, and therefore ethics committee approval is not a requirement. The findings of this review will be presented at workshops and conferences, and will be submitted for publication in a peer-reviewed journal.

\section{RATIONALE}

\section{Healthy urban planning}

Expanding urbanisation across our society has become a major health issue for urban population $^{1-3}$ and as such, there is growing interest in urban health determinants. The relationship between urban planning and health is complex and includes social, environmental and economic dimensions. ${ }^{4-10}$ In its report on healthy urban planning, WHO recognises that the state of cities, resulting from planning policies, can have an impact on health,

\section{Strengths and limitations of this study}

A new and original exploration on the link between urban setting, green spaces and cancer never performed before is presented.

- A feasible strategy to identify knowledge gaps within the last decade years.

- An enlightenment of causal pathways between cancer and green spaces in urban settings in order to provide recommendations on intervention and policies.

well-being and quality of life. ${ }^{6}$ Urban planning includes areas such as housing, transport, water (supply, drainage or sanitation), waste management and green space.

\section{Green spaces as a component of healthy urban} planning

Healthy urban planning connects with recent research into the relationship between nature conservation and health. This is not something new; Hickman has shown that this was already an issue back in 19th century Britain when the National Health Society took an early interest in the urban parks movement. ${ }^{11}$ At the time, green spaces were already looked on as the 'lungs' of the city: 'a park in the East End of London would probably diminish the annual deaths by several thousands, prevent many years of sickness and add several years to the lives of the entire population' (Hickman, p115). ${ }^{11}$

\section{Green spaces and health}

Today urban green spaces are of growing interest to public health experts and citizens alike. While research first focused on risk factors relating to green spaces, scientists are now looking at salutogenic factors. ${ }^{12-15}$

Studies have shown that access to green spaces is associated with better mental and physical health. ${ }^{21617}$ A recent WHO review has shown that green spaces promote relaxation and this may impact on the immune 
system. They also have a positive influence on managing chronic diseases such as hypertension, type 2 diabetes and cardiovascular disease (CVD). ${ }^{18} 19$ Urban green spaces encourage healthier behaviours such as physical and leisure activities. ${ }^{20} 21$ They can also provide recreational settings and promote social cohesion. ${ }^{22}$ Their physical features, nature and size all contribute to regulating urban ecosystems by depolluting the air and improving the quality of the soundscape and the heat island effect. ${ }^{23}$ Other improvements to urban living include amenity green spaces, green path, flowerbeds in urban areas and flower and plant walls. Exposure to sunlight can boost vitamin D supply, regulate the circadian rhythm and quality of sleep. More recent findings suggest that these features contribute to the health benefits generated by green spaces and improve perceived quality of life in inhabitants. ${ }^{25} 26$ These features are also important in that they allow people to encounter different animal and plant life, which may or may not be positive. ${ }^{172728}$

\section{Green spaces and cancer}

Green spaces can have a direct impact on cancer or on intermediary determinants of cancer. ${ }^{29}$

Several studies have underline the link between green spaces and cancer. Some have shown some positive effects suggesting that green spaces may reduce the risk of cancer in the population by enabling healthy lifestyles and health behaviours. ${ }^{30}$ Among different cancer risk factors, there are those which are directly linked to green spaces as risk areas or protective areas (ultraviolet rays, phytosanitary products and air pollution) and those which are indirectly linked (level of physical activity, sedentary lifestyle and obesity mental health).

Green spaces may improve survival rates in ill or convalescent people, and be beneficial for cancer remission. ${ }^{31}$ Other articles suggest some negative effects, for example, through the exposure of pollutants. ${ }^{32}$ Here, some green space management policies may be detrimental to health. This includes the use of phytotoxic products such as pesticides and herbicides, of factors of vector-borne diseases.

Along with other determinants for chronic diseases such as cancer, these factors can lead to positive and negative outcomes. Also as outdoor recreation areas, green spaces may expose users to an excess of ultraviolet rays, which can be a factor leading to skin cancer. ${ }^{33}$ However, the same article highlights that recent research also suggests that UV $\square$ induced release of nitric oxide from skin may have unexpected health benefits, including lowering the incidence of hypertension and CVD that is particularly associated with lower latitudes and winter months.

\section{OBJECTIVES}

This scoping review takes place within the GoveRnance for Equity ENvironment and Health in the City
(GREENH-City - ethical approval CERES 2017- 36) project which focuses on this question and aim to identify links between green space and cancer genesis. We focus on urban setting where green spaces are supposed to have a positive effect on health.

Today, green spaces policies are an issue in urban setting. However, despite the interest in urban green spaces, little research has so far been conducted into the links between green spaces and cancer. Plus, green spaces management in urban settings depends on urban interventions from the local authority. These interventions may directly influence quality of products, types of plants and regeneration of urban green spaces.

Our goal is to explore the relationships between green spaces and cancer and help identify factors that may influence the relationship between green space and cancer. To do so, we will systematically review all the evidence to describe the characteristics of green spaces that have an effect on cancer.

There is no universally accepted definition of 'green spaces'. Therefore, we will define urban green space as 'natural surfaces or natural settings which include specific types of urban greenery, such as street trees and may also include blue space which represents water elements like fountains, ponds or lakes'. ${ }^{19}$

The findings will support public health practitioners, decision-makers and local authorities who are developing policies concerning green spaces.

\section{METHODS AND ANALYSIS \\ Design}

Scoping review was found to be the most appropriate for mapping the existing literature and describe their results, especially when a topic 'has not yet been extensively reviewed' or is complex. ${ }^{34}$ A scoping review of scoping reviews: advancing the approach and enhancing the consistency. ${ }^{35}$ We will conduct the scoping review following the five stages described by Arksey and O'Malley. ${ }^{36}$ Links between green and health is at emerging evidence. As Levac et $a l^{35}$ mentioned, the use of scoping studies allows of incorporating a range of 'study designs in both published and grey literature, address questions beyond those related to intervention effectiveness, and generate findings that can complement the findings of clinical trials'. Arksey and O'Malley proposed a framework for conducting scoping reviews ${ }^{36}$ : (1) identifying the research question; (2) identifying relevant studies; (3) selecting studies; (4) charting the data and (5) collating, summarising and reporting the results.

We followed the Preferred Reporting Items for Systematic Review and Meta-Analysis Protocols (PRISMA-P) 2015 guideline to report the protocol. ${ }^{37}$ Scoping review protocols are not eligible for registration in International Prospective Register of Systematic Reviews. 


\section{Data selection}

Search for electronic databases

We will search MEDLINE (via PubMed), GreenF ILE (via EBSCO host), Cumulative Index to Nursing and Allied Health Literature (via EBSCOhost) and Science Direct as electronic databases. To conduct this scoping review, we will use a structured search strategy based on controlled vocabulary and relevant key term. The key terms for the inclusion criteria are related to green space, urban space and cancer. The search terms and equations for MEDLINE can be found in online supplementary appendix 1 and will be adapted for other databases. We will also screen reference lists of included studies.

\section{Search for other resources}

Google and Google scholar will be also examined. We will also hand-search websites of key organisations involved in addressing and reporting research on green spaces (WHO, Agency for Healthcare Research and Quality, National Institute for Health and Care Excellence (NICE), Medical Research National Institute (INSERM), French National Cancer Institute, The Institute of Cancer Research, Commission for Architecture and the Built Environment, national urbanism agencies, etc) and grey literature databases (eg, OpenGrey). We will screen all the reference lists of included studies (backward search) for new article and search articles (forward search) that have cited the included studies (Web of Science).

\section{Data analysis}

\section{Eligibility criteria}

- All types of studies (randomized controlled trial, prospective cohort studies, case studies, observational studies, non-comparative studies) are eligible for inclusion, including grey literature. We will not select studies on their methodological design and quality. We will limit our search to publications in English, French and Spanish. No date restriction will be applied.

- Reports that document any type of link between urban green space and cancer in human beings.

\section{Exclusion criteria}

- Studies relating to contamination hazards in agricultural soils as well as cemeteries.

- Articles such as commentary, editorial reviews and opinion articles.

\section{Data extraction items}

In order to identify the type relationships between urban green spaces and cancer, the characteristics of green spaces that have an effect on cancer, and the factors which may influence the relationship between green space and cancer, we will extract the following data for the academic and grey literature data:

- study characteristics (title, author and date of publication, journal, country);

- aim and methods;

- context;

- study objectives;
- study design;

- methods;

- population: type of participants, settings and sample size;

- green space characteristics: type of green space, method to characterise green space, contributive factor related to green space that has an effect on cancer;

- if there is a green space intervention, its aim (create, change, remove and improve green spaces), its setting (brownfield intervention and area regeneration, combination with blue spaces, gardening and edible green spaces, schools and institution setting);

- outcomes: type of measures reported to evaluate effects of urban green spaces on cancer, type of green spaces effects;

- effects on cancer: type of cancer involved, type of exposure, relation to exposure (indirect or direct);

- other links/relationships (issues that might be of interest addressed by the study).

\section{Data management}

We will download the references retrieved from the electronic database searches and from the hand searching to Covidence (https://www.covidence.org/) and remove duplicates.

All identified references screened independently by two reviewers (from pool of five authors: MP, ML, MG, JP, J-PR) using a three-stage approach to reviewing the title, abstract and full text. The results of this selection process will be documented in a standardised flowchart. Any potential disagreement will be recorded and resolved by further discussion. We will keep a record of reasons for excluding studies.

Two authors will independently extract information for the first stage. Any potential disagreement will be recorded and resolved by further discussion. For the other stages, the members of the research team will screen the full text and extract the relevant data. To support this process, we will pilot test a data extraction form and test it on five studies. It will be modified when necessary to ensure comprehensiveness and comparability between results. Tables will be prepared in Excel sheets to extract the data where relevant information will be reported

\section{Data synthesis}

We do not plan to perform meta-analyses and statistical methods of synthesis in this review due to the heterogeneity of the identified evidence, The purpose of a scoping review is to aggregate the findings and provide a narrative synthesis.

Quantitative data will be report using descriptive numerical summary analysis.

A qualitative synthesis will be used to describe the key characteristics of urban green spaces and cancer populations, the relationships between urban green spaces and cancer. If additional data emerge, they will be reported with the findings. We will summarise publications and 


\begin{tabular}{|c|c|}
\hline $\begin{array}{l}\text { Strength of } \\
\text { evidence }\end{array}$ & Type of evidence \\
\hline Strong & $\begin{array}{l}\text { Consistent findings in two or more studies } \\
\text { of }++ \text { quality }\end{array}$ \\
\hline Moderate & $\begin{array}{l}\text { One study or consistent findings in two or } \\
\text { more + quality }\end{array}$ \\
\hline Limited & $\begin{array}{l}\text { Only one + study, two or more studies with } \\
\text { inconsistent findings }\end{array}$ \\
\hline No evidence & $\begin{array}{l}\text { No study of acceptable quality }(-) \text {, } \\
\text { inconsistent findings or no relevant research } \\
\text { available }\end{array}$ \\
\hline
\end{tabular}

++ , very low risk; +, low risk; -, high risk of confounding, bias or chance.

their characteristics in tables to support the narrative synthesis. We will create a table that will constitute our map of the literature to present interventions and outcomes that aim to address relationships between urban green spaces and cancer. We will use the method described by the International Initiative for Impact Evaluation (http://www.3ieimpact.org/en/evidence/gapmaps/) to build the table.

We will use the approach of level of scientific evidence to drive the conclusions on the relationship between urban green space and cancer.

We will assess the quality of the body of evidence from all the included studies and reports. We will adapt the 'evidence for corroboration' grading system developed by $\mathrm{NICE}^{38}$ for each characteristic identified (see table 1). Each level will take in account the number and methodological quality of the included studies.

We will use the PRISMA statement to guide the reporting of our findings (https://systematicreviewsjournal.biomedcentral.com/articles/10.1186/s 1364 3-016-0279-4).

\section{CONCLUSION}

This review will provide a picture of the current topic of the link between green spaces and health, with a narrowed focus on cancer genesis. By exploring the pathways between green space components and cancer, the findings could have practical implications on how to manage urban green spaces and how policy-makers may make choices which are more conducive to healthy living.

Contributors JPR, MP, ML, MG and JP wrote the original protocol. MP, JPR and JP drafted the paper. NLC, JS, ARLG, SR, ZH and EF revised the protocol and the paper. $M L$ and MG contribute during Master's internship. Besides the main authors (JP, $\mathrm{J}-\mathrm{PR}, \mathrm{MP}$ and $\mathrm{ML}$ ), all the listed authors are involved in the GREENH-City project as researchers (EF, NLC, JS, SR, LC and ARLG) or practitioners (ZH).

Funding Internal: EHESP. External: This work was conducted within the GoveRnance for Equity ENvironment and Health in the City (GREENH-City) project funded by the National Institute for Cancer (subvention number 2017-003-INCA).

Competing interests None declared.

Patient consent Not required.
Provenance and peer review Not commissioned; externally peer reviewed.

Open Access This is an Open Access article distributed in accordance with the Creative Commons Attribution Non Commercial (CC BY-NC 4.0) license, which permits others to distribute, remix, adapt, build upon this work non-commercially, and license their derivative works on different terms, provided the original work is properly cited and the use is non-commercial. See: http://creativecommons.org/ licenses/by-nc/4.0/

C Article author(s) (or their employer(s) unless otherwise stated in the text of the article) 2018. All rights reserved. No commercial use is permitted unless otherwise expressly granted.

\section{REFERENCES}

1. Vlahov D, Freudenberg N, Proietti F, et al. Urban as a Determinant of Health. J Urban Health 2007;84(3 Suppl):16-26.

2. Mutafoglu K, Schweitzer J-P, Jones $\mathrm{H}$, et al. Nature for Health and Equity. Briefing produced by IEEP for Friends of the Earth Europe KEY CONTACTS Role of nature for children and adolescents [Internet]. 2017 https://www.foeeurope.org/sites/default/files/ biodiversity/2017/briefing_nature_health_equity_march2017.pdf (cited 2017 Jul 6).

3. Lachowycz K, Jones AP. Towards a better understanding of the relationship between greenspace and health: Development of a theoretical framework. Landsc Urban Plan 2013;118:62-9.

4. Harris P, Friel S, Wilson A. 'Including health in systems responsible for urban planning': a realist policy analysis research programme. BMJ Open 2015;5:e008822.

5. Corburn J. Healthy city planning : from neighbourhood to national health equity [Internet]: UK. Routledge, 2013:192.

6. Barton H, Tsourou C. World Health Organization. Regional Office for Europe. Healthy urban planning : a WHO guide to planning for people [Internet. London, UK: Spon Press, 2000:184. Published on behalf of the World Health Organization Regional Office for Europe by Spon.

7. United Nations General Assembly. Transforming our world: The 2030 agenda for sustainable development. 2015 https:// sustainabledevelopment.un.org/content/documents/7891Transformi ng\%200ur\%20World. pdf

8. Barton $\mathrm{H}$, Mitcham $\mathrm{C}$, Tsourou C. Healthy urban planning in practice: experience of European cities Report of the WHO City Action Group on Healthy Urban Planning. Geneva, Switzerland: WHO, 2003.

9. Roue-Le Gall JP A. Agir pour un urbanisme favorable à la santé. Rennes, France: EHESP, 2014.

10. CABE. Future health: sustainable places for health and well-being [Internet]. 2009 papers3://publication/uuid/31F60E11-79B5-4F049437-E3D9626CD6AE

11. Hickman $C$. 'To brighten the aspect of our streets and increase the health and enjoyment of our city': The National Health Society and urban green space in late-nineteenth century London. Landsc Urban Plan 2013;118:112-9.

12. Brown T, Cummins S. Intervening in health: The place of urban green space. Landsc Urban Plan 2013;118:59-61.

13. Wheeler BW, Lovell R, Higgins SL, et al. Beyond greenspace: an ecological study of population general health and indicators of natural environment type and quality. Int J Health Geogr 2015;14:17.

14. Seymour V. The human-nature relationship and its impact on health: a critical review. Front Public Health 2016;4:260.

15. Nieuwenhuijsen MJ, Khreis $\mathrm{H}$, Triguero-Mas M, et al. Fifty shades of green: pathway to healthy urban living. Epidemiology 2017;28:63-71.

16. Zufferey J. Relations entre santé et espaces verts et bleus : une synthèse de la recherche empirique, 2003-2014. Nat Sci Sociétés 2016:343-55.

17. Ten Brink P, Mutafoglu K, Schweitzer J-P, et al. The health and social benefits of nature and biodiversity protection. A report for the European Commission (ENV.B.3/ETU/2014/0039). London/Brussels: Institute of European Environmental Policy, 2016.

18. van den Berg M, Wendel-Vos W, van Poppel M, et al. Health benefits of green spaces in the living environment: A systematic review of epidemiological studies. Urban For Urban Green 2015;14:806-16.

19. WHO Regional Office for Europe. Urban green spaces and health. Copenhagen: WHO Regional Office for Europe, 2016.

20. Carpenter M. From 'healthful exercise' to 'nature on prescription': The politics of urban green spaces and walking for health. Landsc Urban Plan 2013;118:120-7.

21. Lachowycz K, Jones AP. Greenspace and obesity: a systematic review of the evidence. Obes Rev 2011;12:e183-9.

22. Dinnie E, Brown KM, Morris S. Reprint of "Community, cooperation and conflict: Negotiating the social well-being benefits of urban greenspace experiences". Landsc Urban Plan 2013;118:103-11. 
23. Hong JY, Jeon JY. Designing sound and visual components for enhancement of urban soundscapes. J Acoust Soc Am 2013;134:2026-36.

24. Brambilla G, Gallo V, Zambon G. The soundscape quality in some urban parks in Milan, Italy. Int J Environ Res Public Health 2013;10:2348-69.

25. Pope D, Tisdall R, Middleton J, et al. Quality of and access to green space in relation to psychological distress: results from a populationbased cross-sectional study as part of the EURO-URHIS 2 project. Eur J Public Health 2015:ckv094-4.

26. Locke $\mathrm{DH}$, Han S, Kondo MC, et al. Did community greening reduce crime? Evidence from New Haven, CT, 1996-2007. Landsc Urban Plan 2017;161:72-9.

27. Meisser A. et alOperationalizing One Health for Local Governance. In: Zinsstag J, Schelling E, Waltner-Toews D, Whittaker M, Tanner $\mathrm{M}$, . eds. One health: the theory and practice of integrated health approaches. Wallingford \& Boston: CABI Publication, 2015:374-84.

28. Alirol E, Getaz L, Stoll B, et al. Urbanisation and infectious diseases in a globalised world. Lancet Infect Dis 2011;11:131-41.

29. James P, Hart JE, Banay RF, et al. Exposure to greenness and mortality in a nationwide prospective cohort study of women. Environ Health Perspect 2016;124:1345.

30. Dallat MA, Soerjomataram I, Hunter RF, et al. Urban greenways have the potential to increase physical activity levels cost-effectively. Eur $J$ Public Health 2014;24:190-5.
31. Nakau M, Imanishi J, Imanishi J, et al. Spiritual care of cancer patients by integrated medicine in urban green space: a pilot study. Explore 2013;9:87-90.

32. Luo XS, Ding J, Xu B, et al. Incorporating bioaccessibility into human health risk assessments of heavy metals in urban park soils. Sci Total Environ 2012;424:88-96.

33. Liu D, Fernandez BO, Hamilton A, et al. UVA irradiation of human skin vasodilates arterial vasculature and lowers blood pressure independently of nitric oxide synthase. J Invest Dermatol 2014;134:1839-46.

34. Pham MT, Rajić A, Greig JD, et al. A scoping review of scoping reviews: advancing the approach and enhancing the consistency. Res Synth Methods 2014;5:371-85.

35. Levac D, Colquhoun H, O'Brien KK. Scoping studies: advancing the methodology. Implement Sci 2010;5:69.

36. Arksey H, O'Malley L. Scoping studies: towards a methodological framework. Int J Soc Res Methodol 2005;8:19-32.

37. Shamseer L, Moher D, Clarke M, et al. Preferred reporting items for systematic review and meta-analysis protocols (PRISMA-P) 2015: elaboration and explanation. BMJ 2015;349:g7647.

38. Weightman A, Ellis S, Cullum A, et al. Grading evidence and recommendations for public health interventions: developing and piloting a framework [Internet]. London: Health Development Agency, 2005 